\title{
Invasive intracystic papillary carcinoma of the male breast: A case report of a 79 year male with advanced breast cancer at presentation
}

\author{
Der Muonir Edmund ${ }^{* 1,2}$, Bandoh $\mathrm{JD}^{3}$, Robilu $\mathrm{M}^{2}$, Mainatu $\mathrm{G}^{3}$, Kyereh $\mathrm{M}^{3}$ \\ ${ }^{1}$ Department of Pathology, School of Medicine and Health Sciences of the University for Development Studies, Tamale-Ghana \\ ${ }^{2}$ Department of Pathology, Tamale Teaching Hospital, Tamale-Ghana \\ ${ }^{3}$ Department of Surgery, Tamale Teaching Hospital, Tamale-Ghana
}

Received: February 28, 2019

Accepted: March 18, 2019

Online Published: December 23, 2019

DOI: $10.5430 /$ crcp.v7n1p1

URL: https://doi.org/10.5430/crcp.v7n1p1

\begin{abstract}
Published data on male breast cancers (MBCs) are scare in Ghana. We report a case of breast cancer in a 79-year old man, who presented at the Tamale Teaching surgical unit with a clinically advanced stage of the disease. He had modified mastectomy and an invasive intracystic papillary cancer was diagnosed histologically. Immunohistochemically, this tumour was ER+/PR+/HER2However, hormonal therapy could not be started, for the 79-year old before he died in the third week after being discharge from the hospital.
\end{abstract}

Key Words: Intracystic papillary, Male breast cancer, Advanced stage, Immunohistochemistry, Tamale, Ghana

\section{INTRODUCTION}

Carcinoma of the male breast (MBC) is a relatively rare disease world-wide. ${ }^{[1-7]}$ For instance in 2003, it accounted for $1 \%$ of all male cancers in the United States of America (USA). ${ }^{[2]}$ In contrast to the increasing incidence of female breast cancer $(\mathrm{FBC})$, the incidence of $\mathrm{BC}$ in men has remained stable over the past years. ${ }^{[3]}$ Very little data exist in Ghana on male breast cancer. ${ }^{[8,9]}$ Therefore; issues concerning $\mathrm{MBC}$ are under discussed worldwide compared to daily discussions and efforts to control FBC. The earliest reference to MBC dates from 3000-2500 BCE, on an Egyptian papyrus, ${ }^{[10]}$ and the first clinical report was by John of Arderne ${ }^{[11]}$ in the 14 th century. The incidence of MBC is higher in the USA, UK and parts of Africa, but and is lower in Finland and Japan. ${ }^{[12]}$ The reasons for the high incidence of MBC in parts of Africa is unclear but could be explained by an increased incidence of liver disease (a known risk factor for male BC) in these countries. ${ }^{[12]}$

The median age of diagnosis of MBC is 68 years (range: 5-93 years), approximately 5-10 years later than in women. ${ }^{[11,13]}$ The incidence increases with age and the bimodal age distribution seen in women is absent in men. ${ }^{[13]}$ The most common clinical presentation of male breast cancer is a painless subareolar mass. ${ }^{[14]}$

There are very few previous publications of MBCs in Ghana and these were based on core needle biopsies with little information on the prognostic factors. We report a case of an advanced breast cancer in a 79-year old man that was diagnosed in a modified radical mastectomy specimen.

\footnotetext{
*Correspondence: Der Muonir Edmund; Email: maadelle@yahoo.com; Address: Department of Pathology, School of Medicine and Health Sciences of the University for Development Studies, PO Box 1350, Tamale-Ghana.
} 


\section{CASE REPORT}

\subsection{History}

A 79-year-old man presented to the Surgical out-patients unit of the the Tamale Teaching Hospital with slow growing left breast lump. The lump started as a soft small swelling which later became large and ulcerated. He denied any herbal treatment. He noticed the lumps years ago, a first excision was done but he cannot remember the date, but admitted that no histopatholgical studies were conducted. He lives in Wurshe, a suburb of the Tamale Metropolis in the northern region of Ghana. He has no identifiable risk factors.

On examination the lump was ill-defined, measures $12.0 \mathrm{~cm}$ in its widest dimension, ulcerated, bleeds easily, fixed to the chest wall and the skin (Clinically). The axillary lymph nodes were enlarged and matted together.

Initial diagnostic core needle biopsy performed was reported by the pathologist as an invasive papillary carcinoma of the breast. Following this, he had a toilet mastectomy. At surgery the tumour was found to have infiltrated the pectoraris muscle, so some muscle fibres were resected to gather with the tumour. Skin closure was difficult, so a skin grafting was performed.

\subsection{Histopathology}

Macroscopy: We received mastectomy specimen measuring $14.0 \mathrm{~cm} \times 8.0 \mathrm{~cm} \times 3.5 \mathrm{~cm}$ with 2 attached sutures that were not identified (Laterality). The skin measures $14.0 \mathrm{~cm}$ and showed three ulcerated nodular areas (see Figure 1). No attached axillary tail. Slicing the breast reveals a solid tumour with cystic components. The tumour spans the entire breast with involvement of the deep resection margin. The cysts contain greenish gelatinous semi-solid material. The solid component is nodular and cream coloured with projection into the cystic cavities. There were areas of haemorrhages (see Figure 1).

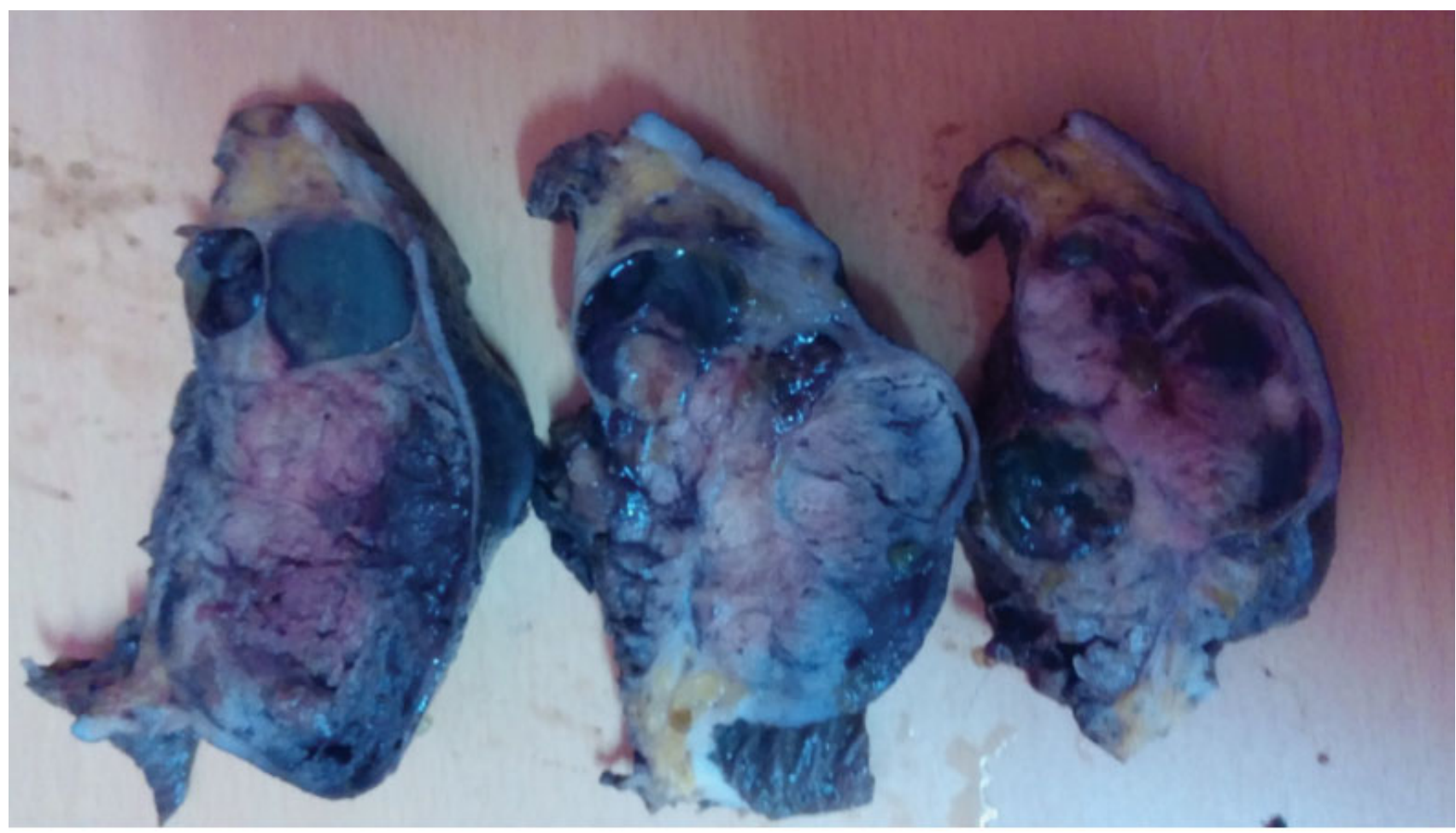

Figure 1. Sections of male mastectomy specimen showing tumour with solid and cystic areas with haemorrhages. The deep resection marging is involved by the tumour

Microscopy: Sections of representative portions of the mastectomy specimen show an ulcerated malignant tumour with solid and cystic components. The solid component is composed of a complex papillary lesion with projections into the cystic cavities (see Figure 2). The fibrovascular cores are lined by moderately pleomorphic cells with nuclei over- lapping nuclei. The lesion involves the skin, the lateral and medial margins, as well as and the deep (skeletal muscle) resection margin. There was a single positive intra-mammary lymph node at the lateral margin. So the diagnosis of invasive intracystic papillary carcinoma,; pT4bN1Mx, with skin infiltration was made. 

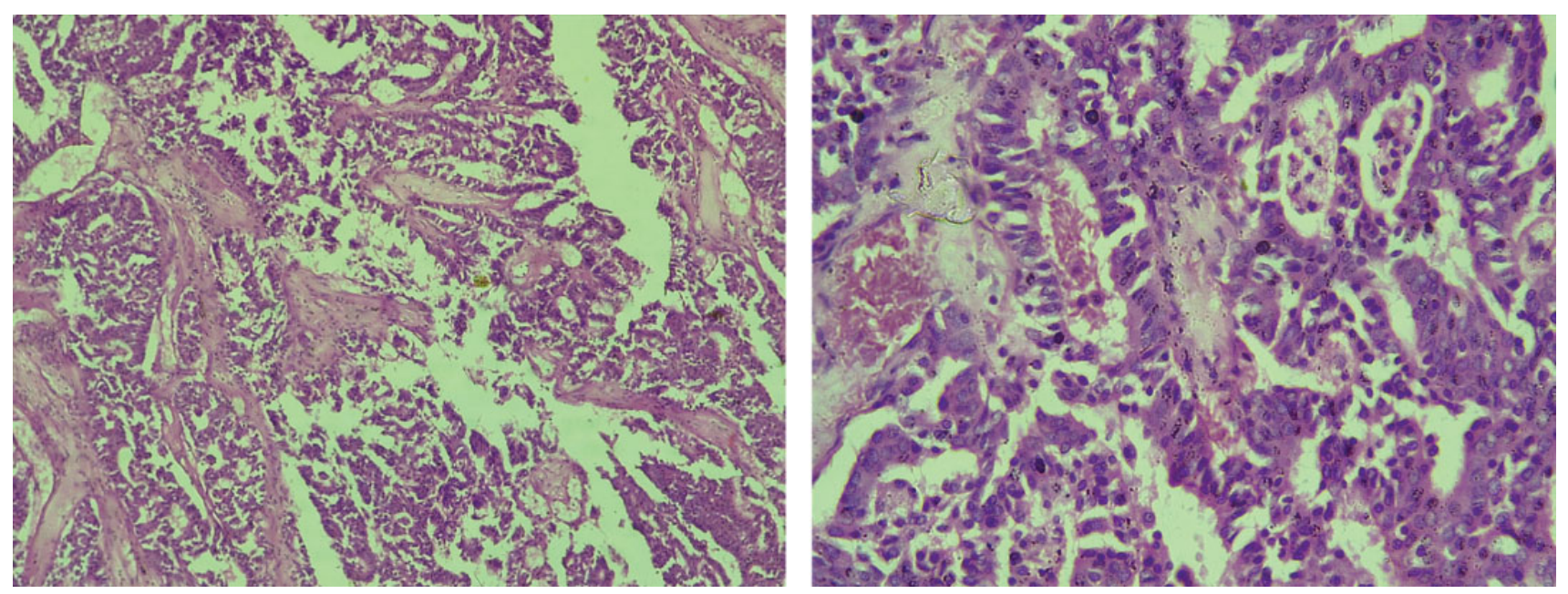

Figure 2. H\&E section of a male breast showing papillary pattern of growth at $x 10$ and $x 40$

Immunohistochemical studies: We performed immunohistochemical staining to determine the expression of steroid hormone receptors according to J-score and Hercep TestTM (DACO Corporation, Carpinteria, California, USA) to deter-

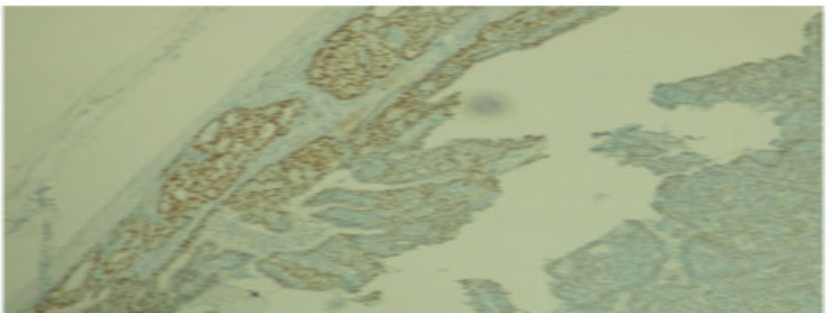

mine the expression of human epidermal growth factor. As shown in the Figures 3-5 and table in Table 1, the tumour was hormonal positive (ER+, PR+/HER2-).

Figure 3. Male breast showing estrogen receptor (ER) positive staining at $x 10$ and $x 40$
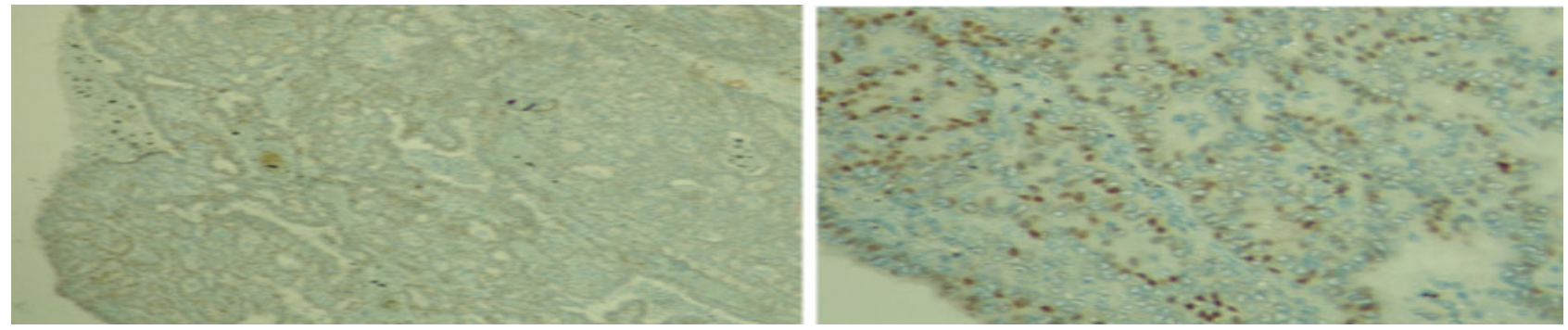

Figure 4. Male breast showing progesterone receptor (PR) positive staining at $x 4$ and $x 40$
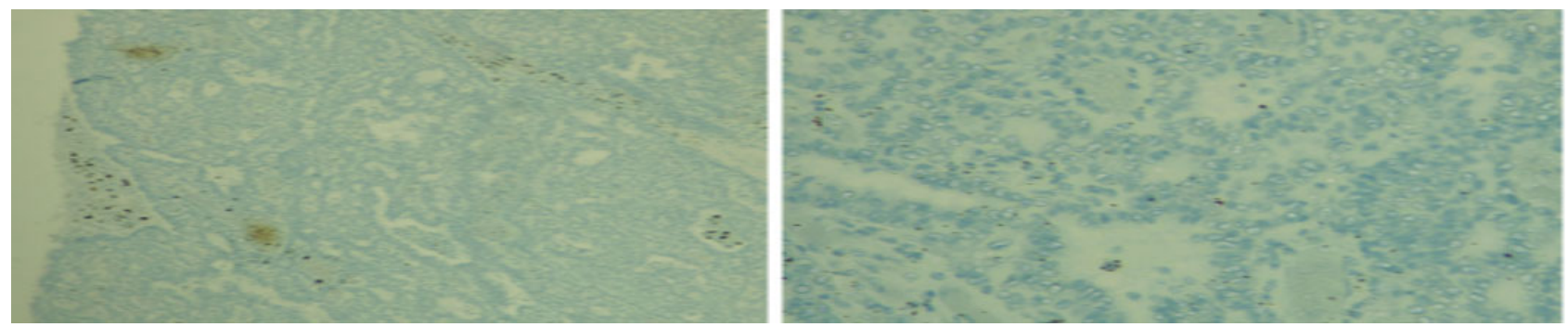

Figure 5. Male breast showing lack of HER2 expression by tumour cells at $x 4$ and $x 40$ 
Table 1. Immunohistochemistry result

\begin{tabular}{llllll}
\hline & $\begin{array}{l}\text { \% Tumour } \\
\text { Score }\end{array}$ & $\begin{array}{l}\text { Intensity score of } \\
\text { staining }\end{array}$ & $\begin{array}{l}\text { Membrane } \\
\text { staining }\end{array}$ & $\begin{array}{l}\text { Total } \\
\text { Score }\end{array}$ & $\begin{array}{l}\text { IHC } \\
\text { Result }\end{array}$ \\
\hline ER & $<1 \%(1)$ & Strong staining (3) & - & 4 & Positive \\
PR & $<1 \%(1)$ & $\begin{array}{l}\text { Moderate staining } \\
\text { (2) }\end{array}$ & - & 3 & Positive \\
HER & - & - & 0 & 0 & Negative \\
\hline
\end{tabular}

DISCHARGE: He was discharge on post-operative day 7th He however died on the third week after he was discharge from the hospital and thus the hormone therapy was not started.

\section{Discussion}

The global burden of male breast cancer has generally been estimated to be low and hence an uncommon disease. ${ }^{[1-5]}$ For instance, Anderson et al., (2005) reported the incidence of male breast cancer to be 1 per 1,00,000 per annum globally. ${ }^{[5]}$ Invasive papillary carcinoma of the male breast, a histological subtype is also reported to be uncommon, more so the intracystic variant, which reported in this current case report, is found to be extremely uncommon with only a few cases reported in the available literature globally. ${ }^{[6,7]}$

The reported incidence of male breast cancer in Africa is similarly very low and these are mostly from core needle biopsy specimens compared to female breast cancer. ${ }^{[1,5]}$ The incidence of the disease is relatively low in the developing countries compared to the developed countries such as the UK and the USA. ${ }^{[2,3,5]}$ The low incidence in Africa may be due to under reporting. Thus an accurate diagnosis of this subtype is essential.

There are two previous studies in Ghana on male breast cancer, but none reported invasive papillary cancer as a histological subtype of male breast cancer. ${ }^{[8,9]}$ For instance, Akosa et al., (2005) study at the Korle-Bu teaching hospital in Accra, the largest referral hospital in Ghana, had no single case of invasive papillary male cancer was identified. There were $(77.8 \%)$ invasive ductal carcinomas with $11.1 \%$ each of invasive lobular and mucinous carcinomas respectively. This further supports the fact that, this subtype of male breast is extremely rare in our country Ghana.

The 79 years old man presented in this current case report was diagnosed histologically with invasive intracystic papillary carcinoma of the breast. Male breast cancers are commonly diagnosed in the elderly (Mean age of 68 years) and the incidence has been found to increase with advancing age. His age was thus a risk factor for his disease. ${ }^{[10-13]}$ He presented with a large ulcerated left breast lump (12.0 $\mathrm{cm}$ ) of many years duration and this was found clinically to be attached to the left anterior chest wall with enlarged axillary lymph nodes. The commonest clinical presentation of male breast cancer is a palpable lump, ${ }^{[8]}$ as in this case, but the size of his tumour although within the range of values $(0.5-12.5 \mathrm{~cm})$ found in the literature ${ }^{[11-13]}$ was very large for this elderly male and this may have to do with long duration of the disease before final diagnosis. Furthermore, the large tumour size, ulceration, fixation to anterior chest wall with difficulties encountered in separating the breast tissue from the skeletal muscles, and the palpable axillary lymph nodes in the current case report were all features of a clinically advanced and neglected disease, judging from the normal size of a non-neoplastic male breast. These findings however, are similar to the advanced presentation of female breast cancer in Ghanaian women. ${ }^{[14]}$ The duration at presentation of this case was very late (years), judging from the fact the initial lesion was excised sometime in the past without histopathological examination. Late presentation of malignant tumours in Ghana, particularly the FBC has been reported decades ago, ${ }^{[15]}$ for which several reasons have been attributed. ${ }^{[16,17]}$ For instance, Ohene et al., ${ }^{[11]}$ study on the spectrum of complaints presented at a specialist breast clinic in Kumasi Ghana identified the painless nature of $\mathrm{BC}$ and the fact that the disease may disappears as the major reasons for the late presentation. Again, Clegg-Lamptey et al., ${ }^{[17]}$ in their study on presentation of BC in Ghanaian women identified bad experience from previous medical consultation and ignorance about the disease; going to prayer camps and the use of herbal treatments by the women as the major similarly have accounted for the advanced presentation of the breast cancer in this case report. The location of $\mathrm{BC}$ in this current case was on the left breast, similar to other publications. ${ }^{[18]}$

Several risk factors have been identified in the published literatures that are implication in the pathogenesis of MBC. These include; hormonal receptor mutation, testicular abnormalities, liver disease, benign breast diseases, drugs and environmental factors. ${ }^{[19,20]}$ Identifiable risk factors were lacking in this current case report, except the advanced age at diagnosed.

Histologically, the tumour was diagnosed as invasive intracystic papillary carcinoma with nodal involvement and positive tumour margins. The tumour was also found by immunohistochemical studies to be ER+/PR+/HER2-. Nodal involvement by malignant tumour and the presence of positive tumour margins are indicators of systemic disease, recurrence after surgery and treatment failure. ${ }^{[21-23]}$ The immunohistochemical profile of this case is in keeping with a previous study conducted at the Korle-Bu teaching Accra Ghana on MBCs. ${ }^{[9,24]}$ The breast cancer by pathological staging was of a high stage (pT4bN1M), in keeping with reports on male breast cancer. ${ }^{[25,26]}$ 
Markers of poor prognosis in male breast cancer have been reported decades ago to include: large size of the primary tumour, high histological grade and stage, and hormone receptor status. ${ }^{[25,26]}$ The others are the advanced age of patient at diagnosis, late stage at presentation with skin ulceration and inflammation leading to increased lymphatic flow tumour spread. ${ }^{[25,26]}$ Furthermore, the innate difference in biological aggressiveness of the male tumour has also be attributed to the proximity to the chest wall, with shorter lymphatics draining into the internal mammary nodes, thus allowing rapid dissemination of tumour. ${ }^{[27]}$

Our patient has most of these poor prognostic indicators. ${ }^{[22-28]}$ For instance, he was 79-years with large tumour size, skin ulceration, fixation to the anterior chest wall with high pathological stage at diagnosis and hence the poor outcome (death) in this case.

\subsection{Conclusion}

MBCs are uncommon, but may presents very late with advanced clinical features suggestive of a neglected disease as in this case. The advanced stage of presentation of MBC may be attributed to lack of information on the disease, low perception of its existence by clinicians and the availability and accessibility of alternative medicine that prevent seeking orthodox medicine. Educational campaign and awareness creation on the existence of MBC at all levels of education and social gathering on self-breast examination, early reporting of detected abnormalities and early and appropriate management are required to reduce the morbidity and mortality associated with the disease.

\subsection{Limitations}

(1) Patient should have had six cycles neoadjuvant chemotherapy but this was not possible because the hospital had ran out of the chemotherapy drugs.

(2) Patient had skin graft immediately after surgery for a tumour that was incompletely excised.

(3) Patient could not be followed-up because he died in the third post-operative week.

\subsection{Recommendations}

(1) Health education on the occurrence of male breast cancer, the risk factors should be in-cooperated into the ongoing female breast cancer campaign.

(2) Males should be encouraged to do self-breast examination and report any abnormality to a health facility for diagnosis and appropriate management.

(3) Patients and patient relatives should be education on the need for early reporting btreast abnormalities.

(4) The importance of histopathological examination of tissues/lumps surgically remlove from patients should be carefully explained to clinicians, patients and their relatives.

\section{ACKNOWLEDGEMENTS}

We wish to express our profound gratitude to the deceased son for the verbal consent and to all staff of Der Medical Diagnosis Centre Limited, Tamale for their valuable support.

\section{CONFLicts OF INTEREST Disclosure}

We obtained verbally permission from the Mr IF son, a biomedical scientist working at the Tamale Teaching Hospital.

\section{REFERENCES}

[1] Paul Ndom, Germaine Um, Esther Mbassi Dina Bell, Albertine Eloundou, et al. Meta-analysis of male breast cancer in Africa. The Breast. 2012; 21: 237-241. PMid:22300703. https://doi .org/10.101 6/j.breast. 2012.01.004

[2] Akosa AB, Ampadu FO, Tettey Y. Male breast cancer in Ghana. Ghana Med J. 1999; 33: 3-8.

[3] Giordano SH, Cohen DS, Buzdar AU, et al. Breast carcinoma in men: a population-based study. Cancer. 2004; 101: 51-57. PMid:15221988. https://doi.org/10.1002/cncr. 20312

[4] Rosen PP, Oberman HA. Carcinoma of the male breast. In; Rosen PP, Oberman HA(edi). Atlas of tumor Pathology. Tumor of the Mammary Gland. AFIP. Washington DC; 3rd series, Fascicle 7: 1992: 287 - 91.

[5] Anderson WF, Devesa SS. In situ male breast carcinoma in the Surveillance, Epidemiology and End result data base of the National Cancer Institute. Cancer. 2005; 104: 1733- 41. PMid:16138363. https://doi.org/10.1002/cncr.21353

[6] Andres B, Aguilar J, Torroba A, et al. Intracystic papillary carcinoma in the male breast. Breast J. 2003; 9: 249-50. PMid:12752638. https://doi.org/10.1046/j.1524-4741.2003.09314.x

[7] Kinoshita T, Fukutomi T, Iwamoto E, et al. Intracystic papillary carcinoma of the breast in a male patient diagnosed by core needle biopsy: a case report. Breast. 2005; 14: 322-4. PMid:16085239. https://doi.org/10.1016/j.breast.2004.12.003

[8] Jemal A, Murray T, Samuel A, et al. Cancer statistics, 2003. CA Cancer J Clin 2003.

[9] Akosa, AB Van Norden S, Tettey Y. Hormone Receptor Expression in Male Breast Cancers. Ghana Med J. 2005 Mar; 39: 14-18. PMid:17299535. https://doi.org/10.4314/gmj . v39i1. 3597 6

[10] Breasted JH. The Edwin Smith Surgical Papyrus. Chicago, University of Chicago Press; 1930: 403-406.

[11] Ravandi-Kashani F, Hayes TG. Male breast cancer: a review of the literature. Eur J Cancer. 1998; 9: 1341-1347. https://doi .org/ 


\section{$10.1016 / \mathrm{S} 0959-8049(98) 00028-8$}

[12] Surveillance, Epidemiology, and End Results (SEER) Program. Public-Use Data (1993-1997) Bethesda, MD: National Cancer Institute, Division of Cancer Control and Population Sciences, Surveillance Research Program, Cancer Statistics Branch. April 2000.

[13] Giordano SH, Buzdar AU, Hortobagyi GN. Breast cancer in men. Ann Intern Med. 2002; 137: 678-687. PMid:12379069. https: //doi.org/10.7326/0003-4819-137-8-200210150-00013

[14] Edmund DM, Naaeder SB, Tettey Y, et al. Breast cancer in Ghanaian women: what has changed? Am J Clin Pathol. 2013; 140: 97-102. PMid:23765539. https ://doi.org/10.1309/AJCPW7TZLS3BFF IU

[15] Quartey-Papafio JB, Anim JT. Cancer of the Breast in Accra. Ghana Med J. 1980: 159-162.

[16] Ohene-Yeboah M, Amanning EP. Spectrum of complaints presented at a specialist breast clinic in Kumasi. Ghana Med J. 2008; 42: 110113. PMid:19274109. https://doi.org/10.4314/gmj.v42i3. 43612

[17] Clegg-Lamptey JNA, Dakubo J, Attobra YN. Why do breast cancer patients report late or abscond during treatment in Ghana? a pilot study. Ghana Med J. 2009; 43: 127-131. https ://doi.org/10.4 314/gmj •v43i3. 55338

[18] Buzdar AU. Breast cancer in men. Oncology. 2003; 17: 1361-1364

[19] Hansen J. Elevated risk for male breast cancer after occupational exposure to gasoline and vehicular combustion products. Am J Ind Med. 2000; 37: 349-352. https ://doi.org/10.1002/(SICI) 1 097-0274(200004) $37: 4<349:$ : AID-AJIM4>3 . 0 . CO;2-L
[20] Williams MJ. Gynecomastia. Am J Med. 1963; 34: 103-112. https : //doi.org/10.1016/0002-9343(63)90044-5

[21] Wilson RE, Donegan WL, Mettlin C, et al. The 1982 national survey of carcinoma of the breast in the United States by the American College of Surgeons. Surg Gynecol Obstet. 1984; 159: 309-318.

[22] Der EM, Naaeder SB, Clegg-Lamptey JNA, et al. Positive tumour margins in wide local excisions (lumpectomies) biopsies: a 10-year retrospective study. AJPM. 2014; 3, Article ID 235871, 5 pages. https ://doi.org/10.4303/ajpm/235871

[23] Sheikh F, Rebecca A, Pockaj B, et al. Summary of "Inadequate Margins of Excision When Undergoing Mastectomy for Breast Cancer: Which Patients are at Risk?" Ann Surg Oncol. 2011; 18: 952 6. PMid:21080087. https://doi.org/10.1245/s10434-010-1 406-4

[24] Tan PY, SNG ITY. Male breast cancer. A retrospective study with immunohistochemical analysis of hormone receptor expression. Pathol. 1997; 29: 2-6. PMid:9094169. https ://doi.org/10.1080/0031 3029700169444

[25] Crichlow RW. Carcinoma of the male breast. Surg Gynaecol Obstet. 1972; 134: 1011-1019.

[26] Ouriel K, Lotze MT, Hinshaw JR. Prognostic factors of carcinoma of the male breast. Surg Gynae Obstet. 1984; 159: 373-376.

[27] Heller KS, Rosen PP, Schottenfeld D, et al. Male breast cancer: a clinicopathological study of 97 cases. Ann Surg. 1978; 188: 60-65. PMid:208472. https://doi .org/10.1097/00000658-1 97807000-00010

[28] Yildirim E, Berberoglu U. Male breast cancer: a 22-year experience. Eur J Surg Oncol. 1998; 24: 548-552. https ://doi .org/10.101 6/S0748-7983(98) 93608-3 